\title{
THE INFLUENCE OF INCLINATION ANGLE ON VOID FRACTION AND HEAT TRANSFER DURING CONDENSATION INSIDE A SMOOTH TUBE
}

\author{
Stefan P. Olivier ${ }^{1}$, Josua P. Meyer ${ }^{1 *}$, Michel De Paepe ${ }^{2}$ and Kathleen De Kerpel ${ }^{2}$ \\ ${ }^{1}$ Department of Mechanical and Aeronautical Engineering, University of Pretoria, Pretoria, Private Bag X20, \\ Hatfield 0028, South Africa \\ ${ }^{2}$ Department of Flow, Heat and Combustion Mechanics, Ghent University - UGent, Sint-Pietersnieuwstraat 41, \\ 9000 Gent. Oost-Vlaanderen, Belgium \\ *Corresponding author: josua.meyer@up.ac.za, Tel. +27 124203104
}

\begin{abstract}
Most work in literature on condensation in tubes has been done for smooth tubes in the horizontal and vertical configurations. Recent experimental works with condensation at different inclination angles showed that the heat transfer characteristics were a function of inclination angle. These works were limited to heat transfer and pressure drop measurements with visual observations. However, no work has been done on measuring the void fractions during condensation at different inclination angles. The purpose of this study was to measure void fractions and heat transfer coefficients during condensation for tube inclinations ranging from vertical downwards $\left(-90^{\circ}\right)$ to vertical upwards $\left(90^{\circ}\right)$ at a saturation temperature of $40{ }^{\circ} \mathrm{C}$. Measurements were taken in an experimental set-up in which condensation occurred on the inside of a test section. The test section was a circular tube with an inner diameter of $8.38 \mathrm{~mm}$ and a heat transfer length of 1.488 . The refrigerant used was R134a, and the void fractions were measured using two capacitive void fraction sensors. Mass fluxes ranging from $100-400 \mathrm{~kg} / \mathrm{m}^{2} . \mathrm{s}$ and vapour qualities ranging from $10-90 \%$ were considered. Heat transfer coefficients were also compared with void fractions. It was found that at combinations of low mass fluxes and vapour qualities, void fraction and heat transfer were significantly affected by changes in inclination angle. Generally, void fractions and heat transfer coefficients increased with downward inclination angles with an optimum angle between $-10^{\circ}$ and $30^{\circ}$ (downward flow). At some intermediate mass flux and vapour quality conditions, the void fraction and heat transfer coefficients were observed to be independent of the inclination angle despite changes in the prevailing flow patterns.
\end{abstract}


Keywords: Void fraction; two-phase flow; capacitance; flow pattern; condensation; inclination angle; heat transfer coefficient.

\section{Introduction}

Many systems in the air-conditioning and refrigeration industries where cooling and/or heating is required make use of vapour-compression systems. The condenser in the vapour compression system needs to reject heat by condensing the refrigerant from a gas to a liquid.

Other industries where condensation occurs are in the power generation industries where steam is condensed in air and water cooled cooling towers. In the majority of cases condensation occurs in tubes which are configured horizontally. An exception is steam condensation in large air cooled condensers used in the power generation industry where water is not readily available as a cooling medium. These condensers are constructed in an A-frame structure configured to provide condensing flow at an approximate $60^{\circ}$ downward inclination. However, no work has been published in the open literature that justifies this angle. It is therefore not clear if this angle is based on heat transfer and/or structural considerations.

Other applications where condensation occurs in inclined tubes are steam condensers used for aircooling, and also in some rooftop industrial air-cooled refrigeration systems. Again, no work has been published in the open literature which justifies the angles being used.

A recent review of the state of the art in condensation flow was conducted and the conclusion was drawn that the majority of work was done for horizontal tubes and a limited amount in vertical tubes (Lips and Meyer, 2011). However, very little work was done for condensation in inclined tubes. Past work have highlighted the importance of the identification of the prevailing flow pattern since it is used in the development of equations that estimate the local and average heat transfer and pressure drop coefficients during condensation (Da Riva et al., 2012; Doretti et al., 2013; Nebuloni and Thome, 2013; Thome et al., 2013).

Past work on the subject of condensation in inclined tubes found that downward inclination angles could have significant advantages since gravity assisted in thinning the liquid layer inside the tube and reduce the thermal resistance to heat transfer (Lips and Meyer, 2012b).

An increase in heat transfer of up to $20 \%$ at an inclination of $-15^{\circ}$ (downward flow) was observed for combinations of low mass flux and vapour quality. The heat transfer decreased with upward flow inclinations. At higher mass flux and vapour quality conditions, shear forces were dominant, which 
meant that the flow patterns tended to remain annular with the heat transfer coefficients exhibiting independence of the tube inclination angle. Also, the observed flow patterns did not correlate well with the considered models for inclined flow.

From the work of Lips and Meyer (2012c) for horizontal pressure drops, the model of Moreno Quibén and Thome (2007) along with the El Hajal et al. (2003) flow pattern map best represented the experimental results. Void fraction models were chosen by Lips and Meyer (2012c) in order to use pressure drop correlations for comparison with experimental results. The void fraction correlations considered in their study led to a $\pm 25 \%$ agreement between predicted pressure drops and measured pressure drops for upward flows. The correlations failed to predict pressure drops for downward flows. The apparent gravitational pressure drop (which was defined as the difference between the pressure drops for inclined tubes versus horizontal tubes) was used to estimate the apparent void fraction. The apparent void fraction was defined as the void fraction value which would have led to the aforementioned apparent gravitational pressure drop. From the results, it appeared that the void fraction remained constant for upward flows. For downward flows, the apparent void fraction could not be considered to represent the actual void fraction since the frictional pressure drop was dependent on the inclination angle.

At lower mass fluxes (i.e. $100-200 \mathrm{~kg} / \mathrm{m}^{2} . \mathrm{s}$ ), the heat transfer coefficients were observed to exhibit a maximum in the region of $-30^{\circ}$ to $-15^{\circ}$ (downward flow) due to gravity thinning of the stratified liquid layer (Meyer et al., 2014), which led to less thermal resistance. The heat transfer coefficients were observed to reduce with increased saturation temperature for all inclination angles and mass fluxes. The reason provided was that the thermal conductivity of the particular refrigerant (R134a) decreased with increasing temperature meaning a reduction in heat transfer coefficient.

However, what has not yet been looked into is the determination of the void fractions and their influence on heat transfer coefficients in tubes at different inclination angles. The knowledge of the void fractions is important in the developing of accurate heat transfer coefficient equations, which has also not yet been done in inclined tubes.

The challenge is that the heat transfer and pressure drop during condensation in a tube are directly related to the temporal and spatial distribution of the liquid and vapour phases. These phases are directly related to the void fraction and a considerable number of measurements have been taken to relate the void fraction to heat transfer and pressure drop equations during condensation (Adelaja et al., 2014a, 2014b; Meyer et al., 2014). However, no work has been done to determine the void fraction and its influence on heat transfer coefficients during condensation in inclined tubes. In 
addition, no work has been done on the development of new and/or revision of existing equations, which takes into consideration the changes that occur in void fraction as a function of the inclination angle.

Accurate void fraction measurements are challenging, and in most cases where void fractions were measured it was done using only one sensor for the entire test section (Ahmed, 2011; Da Silva et al., 2010; De Kerpel et al., 2013; Demori et al., 2010). This is perhaps not an accurate representation of the average void fraction of a test section that changes between the inlet and outlet. As the void fractions and heat transfer correlations are so strongly related there is a need for accurate void fraction measurements, however, instrumentation that can measure void fractions without influencing the flow patterns are not readily available commercially. Such a void fraction sensor has been developed at the Ghent University (Canière et al., 2010, 2009, 2008, 2007), but is not yet commercially available on the open market.

The purpose of this study was to measure void fractions with two void fraction sensors developed at Ghent University, capture prevailing flow patterns visually and measure the heat transfer coefficients over a wide range of inclination angles during condensation in a smooth tube. The effect of the void fractions on the flow patterns and heat transfer coefficients was also investigated qualitatively.

\section{Experimental apparatus and test conditions}

\subsection{Experimental set-up}

The experimental system (Figure 1) was inherited from past research work in which detailed descriptions and explanations have been provided (Adelaja et al., 2014a, 2014b; Canière et al., 2007; Lips and Meyer, 2012a, 2012b, 2012c; Meyer et al., 2014; Suliman et al., 2009; Van Rooyen et al., 2010). Therefore, only a brief overview will be provided in this section.

The experimental set-up consisted of a vapour compression refrigeration cycle operated with refrigerant R134a, as well as a water cycle. The refrigeration cycle consisted of two high-pressure lines, i.e. the test line and bypass line, through which the condensing fluid was pumped. Fluid flow was obtained using a hermetically sealed scroll compressor with a nominal cooling capacity of 10 $\mathrm{kW}$. The flow of refrigerant through each respective line was controlled using a set of electronic expansion valves (EEVs). 


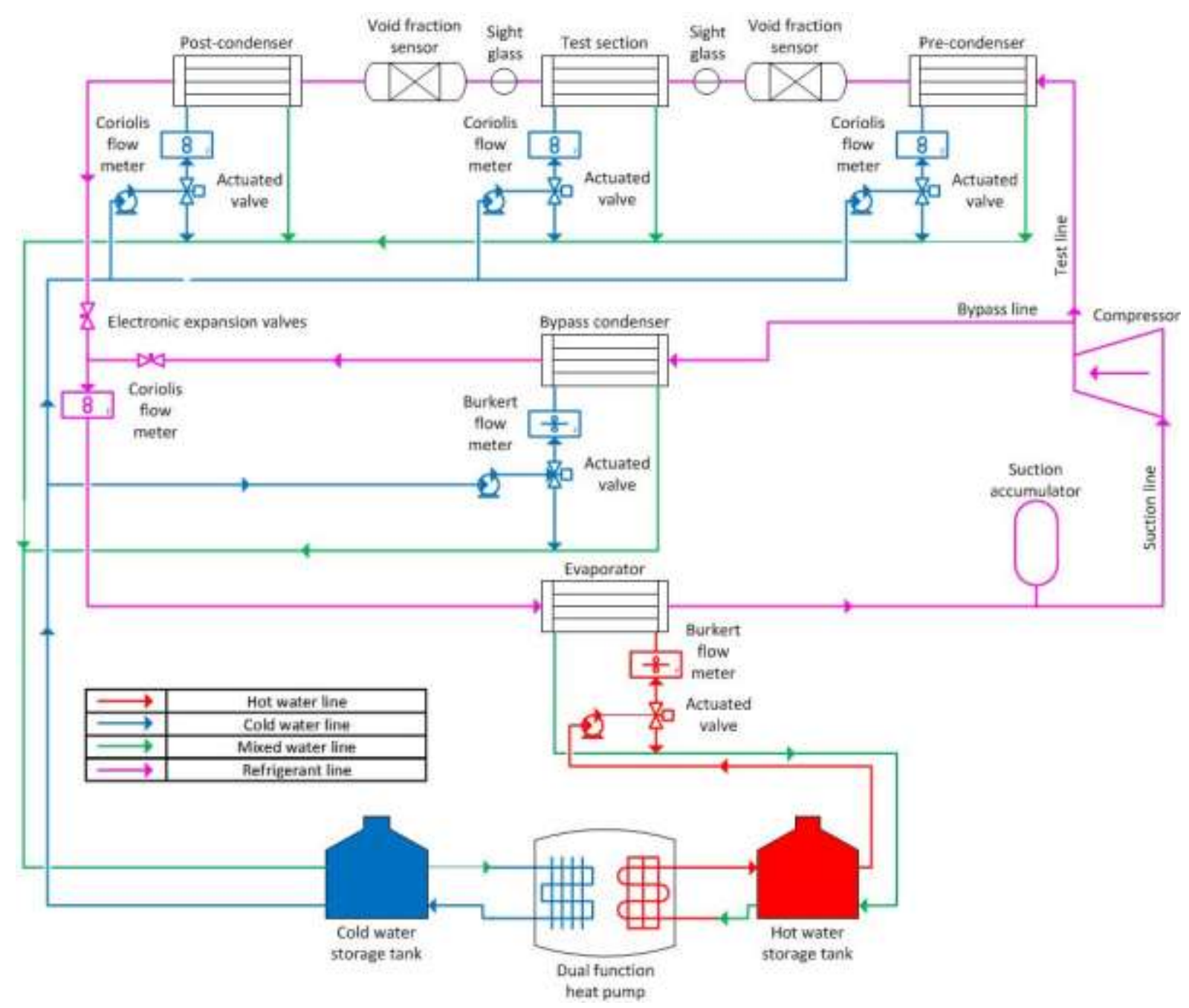

Figure 1: Schematic of the experimental set-up

The test line was served by three respective condensers. A pre-condenser was responsible for controlling the vapour quality at the inlet of the test condenser where temperature, pressure, flow pattern and void fraction measurements were taken. The void fraction measurements were made using sensors which measured the capacitance of the flow with an accuracy of $\pm 4 \times 10^{-15} \mathrm{~F}$. The absolute uncertainty in the void fraction measurements was estimated by the sensors' developers to be 0.02 . Two sensors were used, one at the inlet of the test section and the other at the outlet of the test section. A cross-sectional illustration of the void fraction sensor construction is provided in Figure 2. The internal diameter of the void fraction sensor was $8 \mathrm{~mm}$, the inscribed electrode angle $(\beta)$ was $160^{\circ}$, the tube wall thickness was $50 \mu \mathrm{m}$, and the axial length of each electrode was $8 \mathrm{~mm}$, i.e. one tube diameter. The average of the two measurements was taken as the average void faction in the test section. 


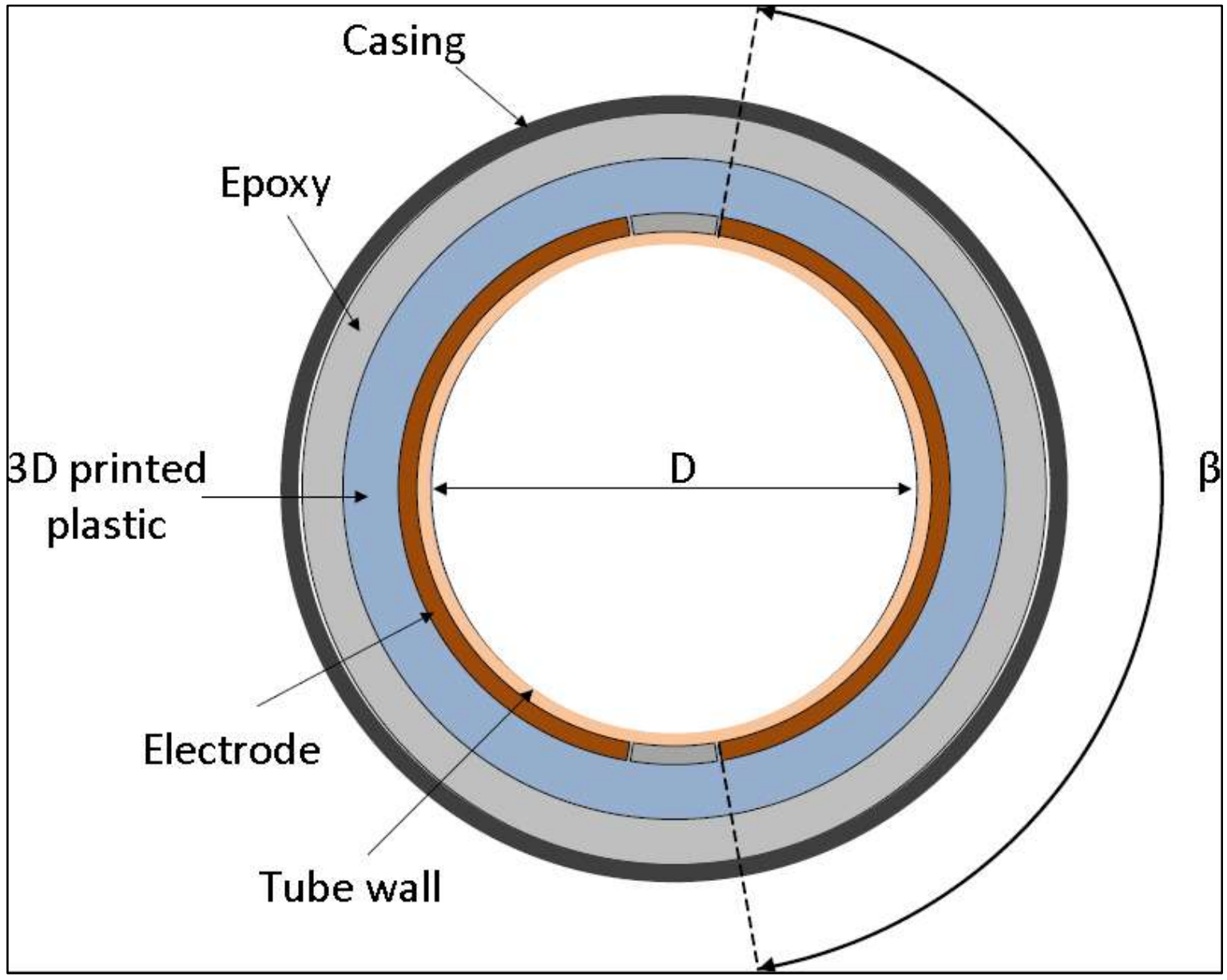

Figure 2: Illustration of cross-sectional construction of void fraction sensors used in current study

A post-condenser ensured that the refrigerant reached the EEVs in a liquid state to ensure accurate mass flow measurements. The bypass condenser controlled the mass flow rate, saturation temperature as well as saturation pressure of the refrigerant in the test section. The bypass condenser was also adjusted so only liquid refrigerant reached the EEV. Downstream of the respective EEVs, the test and bypass lines merged into a single lower-pressure line, which led to the suction of the scroll compressor through an evaporator. A suction accumulator ensured that only vapour was available at the compressor suction.

Hot and cold water was supplied by a $50 \mathrm{~kW}$ heating and $70 \mathrm{~kW}$ cooling dual-function heat pump. Thermostat control was used to maintain the hot water at $25^{\circ} \mathrm{C}-30^{\circ} \mathrm{C}$ and the cold water at $15^{\circ} \mathrm{C}$ $25{ }^{\circ} \mathrm{C}$ respectively in two tanks of 5000 litre capacity each. The hot water was used in the evaporator while the cold water was used in the various condensers mentioned previously.

The test condenser was constructed as a tube-in-tube counterflow heat exchanger with refrigerant flowing in the inner tube and water flowing in the annulus. The inner tube was constructed from an $8.38 \mathrm{~mm}$ inner diameter ( $0.6 \pm 0.002 \mathrm{~mm}$ wall thickness) smooth, hard-drawn copper tube inside an 
outer tube from $15.9 \mathrm{~mm}$ inner diameter smooth, hard-drawn copper tube. This tube diameter was selected for this study as it was used in several previous studies (Adelaja et al., 2014a, 2014b; Lips and Meyer, 2012b, 2012c; Meyer et al., 2014) and therefore better comparisons are possible.

The refrigerant stream flowed through the inner tube and the water stream through the annulus in a counter flow direction. A wire with an outside diameter of $2 \mathrm{~mm}$ was wrapped around the outside of the inner tube at a constant pitch to improve water mixing within the annulus and prevent temperature stratification. The heat transfer length of the test section was measured as $1.488 \mathrm{~m}$. This length was selected to ensure that the results can be compared to previous studies (Adelaja et al., 2014a, 2014b; Lips and Meyer, 2012b, 2012c; Meyer et al., 2014) and to ensure that experiments could be conducted at a full range of inclination angles from vertical downward to vertical upward in a laboratory with physical height limitations. The entire test section was insulated with $60 \mathrm{~mm}$ of insulation with a thermal conductivity of $0.041 \mathrm{~W} / \mathrm{m} . \mathrm{K}$ to minimise heat losses to the ambient air. The inclination angle was measured using a digital inclinometer that was attached at the pivot point of the test section.

To develop the flow as fully as possible at the inlet to the test section a calming section with a length of $260 \mathrm{~mm}$ (31 tube diameters) was situated upstream of the test section. Before any measurements were taken, the effect of the void fraction sensors on heat transfer measurements were investigated by first installing straight-section spool pieces in place of the sensors; this increased the length of the calming section to more than 50 tube diameters. The heat transfer results without the void fraction sensors installed were then compared with the results obtained with the void fraction sensors installed. No significant difference in the heat transfer results could be observed. Therefore, it could be deduced that the presence of the void fraction sensors did not significantly affect the heat transfer and void fraction results. Even so, their axial lengths were not considered as part of the entry length of the test section.

Borosilicate sight glasses ( $\pm 60 \mathrm{~mm}$ in length) were installed at both the inlet and outlet of the test section, which enabled visual observation of the flow patterns. In general it was found that the length of the sight glasses was long enough to ensure that all flow patterns could be clearly observed. However, at low mass flux and vapour quality conditions for upward flow inclinations the liquid slug length was greater than the axial length of the sight glasses.

The sight glasses also insulated the test section against axial heat conduction. A monochromatic high-speed camera set at roughly 200 frames per second was used at the outlet sight glass for flow visualization. To improve the image quality, a uniform light emitting diode (LED) backlight was used. 
The LED backlight was chosen with a low energy output so that it did not thermally affect the passing flow.

Three pressure taps were installed at both the inlet and outlet of the test section respectively. They were affixed to the tube by silver soldering $\pm 20 \mathrm{~mm}$ long capillary tubes on each end of the test section. A $1 \mathrm{~mm}$ hole was drilled through the capillary tube through the tube wall of the test section. A small diameter was desirable to ensure that the pressure taps did not cause flow obstructions in the test section and that the diameter was less than $10 \%$ of the test section's inner diameter (Rayle, 1959). Care was taken to remove all burrs from the inside of the test section which may have an undesirable effect on pressure measurements.

Two of the aforementioned taps were connected to ratiometric pressure transducers, which measured the prevailing absolute pressure at both the inlet and outlet of the test section respectively. The remaining pressure taps were available for differential pressure measurement, which was not considered for the current study. The pressure sensors used to measure the saturation pressure was calibrated and had an uncertainty of $0.1 \%$ relative to its full scale of $3447 \mathrm{~Pa}$.

On the outer periphery of the inner tube, four countersunk indentations were drilled to enable the thermocouples to be affixed by soldering. The indentations were equally spaced around the periphery in such a way that two thermocouples could be located on a plane perpendicular to a stratified liquid interface and two in parallel to form a measuring station. There were seven equidistant measuring stations along the length of the test section. All thermocouples were constructed using T-type thermocouple wire with a 30-gauge thickness $(0.1 \mathrm{~mm})$ and were calibrated to within $\pm 0.1^{\circ} \mathrm{C}$ against a PT100 RTD-device.

Three thermocouples were installed upstream of the inlet sight glass and downstream of the outlet sight glass to measure the prevailing saturation temperature. The saturation temperature was also corroborated by the absolute pressure measurements and the REFPROP (2005) database for refrigerant R134a. The differences in the measured saturation temperature and those determined from the database using absolute pressure measurements were less than $0.1^{\circ} \mathrm{C}$ at high mass fluxes, i.e. $400 \mathrm{~kg} / \mathrm{m}^{2} . s$.

The fluid flow rates of the test section, pre-condenser, test condenser and post-condenser were measured using Coriolis mass flow meters with uncertainties of $0.1 \%$. The mass flow meters were installed upstream of each respective condenser. The Coriolis mass flow meter which measured the 
refrigerant mass flow rate through the test section was situated downstream of the post-condenser and upstream of the EEVs.

The capacitive void fraction sensors used in the current study were developed by Ghent University (Canière et al., 2010, 2009, 2008, 2007) and a calibration procedure was developed for adiabatic horizontal flow (De Kerpel et al., 2014, 2013). For the current study the sensor responses were calibrated to track the predictions of the Rouhani and Axelsson (1970) correlation for the case of horizontal adiabatic flow at a saturation temperature of $40^{\circ} \mathrm{C}$; good correlation between horizontal adiabatic flow and the Rouhani and Axelsson (1970) predictions has been observed in previous work (De Kerpel et al., 2013).

\subsection{Data acquisition and experimental procedure}

A computerised data acquisition (DAQ) system was used to gather the data from the respective measuring instruments. The DAQ system consisted of a personal computer using LabVIEW software with which the measurements could be logged and experimental system could be controlled. The data acquisition package used contained the necessary multiplexers, analogue-to-digital converters and terminal blocks to successfully log the data onto the computer.

After start-up, adjustments were made incrementally to the experimental system until the desired flow conditions were obtained. The system was allowed to stabilise until all parameters (mass flow rates, temperatures, void fraction measurements and pressures) were visually observed to remain constant and steady-state conditions were achieved. The difference between the heat transfer rate on both the water side and refrigerant side was also monitored as the "energy balance error". Once the energy balance was less than $5 \%$ (the average of all measurements was less than $3 \%$ ), and steady state conditions were achieved measurements were made. The heat transfer rate of the water was assumed to be the more accurate and was controlled by the water mass flow rate and inlet temperature to always be $200 \mathrm{~W}$. This ensured that the heat flux of all the condensation experiments was $10.2 \mathrm{~kW} / \mathrm{m}^{2}$. At the lowest mass flux $\left(100 \mathrm{~kg} / \mathrm{m}^{2} . \mathrm{s}\right)$, the energy balances could not always be maintained below $5 \%$ and values of up to $6 \%$ as an exception were reached.

Data capturing of the thermocouple temperatures and the void fractions were done using three different voltage transducer amplifier cards. The DAQ card used for temperature measurements had a frequency range of up to $2 \mathrm{~Hz}$ and the two DAQ cards used for the void fraction measurements had a frequency range of up to roughly $3000 \mathrm{~Hz}$. To enable the void fractions to be captured at a high frequency, the capturing of the temperatures preceded the capturing of the void fraction results for each data point. The temperatures were captured at a frequency of $1 \mathrm{~Hz}$ over a 120 -second time span for each data point, after which the void fraction results were immediately acquired at a 
frequency of $1000 \mathrm{~Hz}$ for a time span of 120 seconds. Several experiments were done at different sampling rates for both the temperatures and void fractions. The experiments were repeated several times and the same results were found for each temperature and void fraction measurement. Measurements were also done where the temperature measurements were captured at the same time as the void fraction measurements and the same results were obtained. The sampling frequency of the void fraction measurements was sufficient as most two-phase flow phenomena occur at a frequency of $100 \mathrm{~Hz}$ (Canière et al., 2007). The Nyquist criterion for sampling was thus satisfied and aliasing of the observed void fraction signals was therefore not a challenge.

\section{Data reduction}

The void fraction results were obtained in a similar fashion to that of past work (De Kerpel et al., 2013). The normalised voltage $\left(V_{\text {Norm }}\right)$ outputs of the capacitive sensors were calculated as follows:

$$
V_{\text {Norm }}=\frac{V_{\text {Measured }}-V_{V}}{V_{L}-V_{V}}
$$

The response of each void fraction sensor to an induced liquid-only condition $\left(V_{L}\right)$ were measured at a temperature of $40^{\circ} \mathrm{C}$ since this differed from the original calibration temperature (De Kerpel et al., 2013). The dielectric constant of refrigerant vapour was shown to be temperature independent (Dos Reis and Goldstein, 2005) and thus the vapour-only response $\left(V_{V}\right)$ of the sensors was obtained at ambient temperature only. Using the measured responses for the liquid-only and vapour-only cases, the denominator in equation (1) for the entire data set was determined. This value was assumed to remain constant for the duration of the current study. The numerator in equation (1) was determined using the raw sensor voltage outputs $\left(V_{\text {measured }}\right)$ as well as an ambient vapour-only measurement $\left(V_{V}\right)$, which was taken daily during the data capturing process before any measurements were taken to account for any drift in the void fraction sensors.

For each respective mass flux, vapour quality and inclination angle condition, the average void fraction over the sampling time was desired. To obtain the average void fraction, each normalised voltage data point was first converted to a void fraction value using the calibration equation (De Kerpel et al., 2013). The coefficients for the calibration equation were however determined specifically for the current study by correlating adiabatic void fraction results to the Rouhani and Axelsson (1970) predictions in accordance with observations made in past research (De Kerpel et al., 2013). The calibration coefficients were determined during adiabatic tests with the two void fraction sensors approximately $2 \mathrm{~m}$ apart from each other. A time-average void fraction for each sensor was calculated using a trapezoidal integration routine on the void fraction results for each data point. 
The average void fraction results for the refrigerant condensing in the test section were taken as the arithmetic mean between the trapezoidal integrated inlet and outlet void fraction values.

To determine the vapour quality of the fluid at the inlet to the test section $\left(x_{T e s t, i}\right)$, the specific enthalpy at the outlet of the pre-condenser $\left(h_{R, \text { PreCond,o }}\right)$ was calculated from the specific enthalpy at the inlet of the pre-condenser $\left(h_{R, \text { PreCond }, i}\right)$, the measured heat transfer rate on the water side of the pre-condenser $\left(\dot{Q}_{H_{2} O \text {,PreCond }}\right)$ and refrigerant mass flow rates $\left(\dot{m}_{R}\right)$ :

$$
h_{R, \text { PreCond }, o}=h_{R, \text { PreCond }, i}-\left|\frac{\dot{Q}_{H_{2} O, P r e C o n d}}{\dot{m}_{R}}\right|
$$

The parameter $h_{R \text {,Precond }}$ was the specific enthalpy of the refrigerant at the inlet and outlet of the pre-condenser (subscripts denote inlet or outlet position), determined from the REFPROP (2005) database for the refrigerant R134a. Heat losses between the pre-condenser and test section were neglected; thus the specific enthalpy was assumed to stay constant from the pre-condenser outlet to the test section inlet. A one-dimensional analysis showed that heat losses to the environment were not significant. The heat transfer through the pre-condenser used in equation (2) was calculated using the measured water mass flow rate $\left(\dot{m}_{H_{2}}\right.$ O,PreCond $)$, specific heat capacity $\left(c_{p}\right)$, and measured water inlet $\left(T_{\text {PreCond }, i}\right)$ and outlet temperatures $\left(T_{\text {PreCond,o }}\right)$ :

$$
\dot{Q}_{\mathrm{H}_{2} \mathrm{O}, \text { PreCond }}=\dot{m}_{\mathrm{H}_{2} \mathrm{O}, \text { PreCond }} c_{p}\left(T_{\text {PreCond }, i}-T_{\text {PreCond }, o}\right)
$$

The temperature and pressure measurements at the inlet to the test section were used along with a refrigerant property database (REFPROP, 2005) to determine the saturated liquid $\left(h_{R, f}\right)$ and vapour $\left(h_{R, g}\right)$ specific enthalpies. The inlet vapour quality was determined as follows:

$$
x_{T e s t, i}=\frac{h_{R, \text { PreCond }, o}}{h_{R, g}-h_{R, f}}
$$

The outlet vapour quality was calculated in a similar fashion to equation (4) using the inlet specific enthalpy $\left(h_{R, T e s t, i}\right)$, which was assumed identical to the pre-condenser outlet specific enthalpy, the outlet specific enthalpy $\left(h_{R, \text { Test,o }}\right)$ and the heat transfer from the water side of the test section $\left(\dot{Q}_{H_{2} O, T e s t}\right)$ as follows:

$$
h_{R, \text { Test }, o}=h_{R, \text { Test }, i}-\left|\frac{\dot{Q}_{\mathrm{H}_{2} O, T e s t}}{\dot{m}_{R}}\right|
$$


The heat transfer rate through the test condenser was obtained by substituting the parameters in equation (3) for those of the test condenser. The outlet vapour quality was then calculated in a similar fashion to equation (4) by substituting the outlet specific enthalpy calculated from equation (5). The average vapour quality was taken as the arithmetic mean between the calculated inlet and outlet values.

The average heat transfer coefficient in the test section $\left(\alpha_{\text {Test }}\right)$ was determined from the wall-, bulk water- and saturation temperature measurements. The water heat transfer rate $\left(\dot{Q}_{\mathrm{H}_{2} \mathrm{O}, \mathrm{Test}}\right)$ measurement was used and not the refrigerant heat transfer rate measurement as the water side was considered to be the more accurate of the two heat transfer rate measurements.

Assuming a constant heat transfer coefficient across the length of the test section, the average heat transfer coefficient of the test section was determined as follows:

$$
\alpha_{\text {Test }}=\left|\frac{\dot{Q}_{\mathrm{H}_{2} \mathrm{O}, \mathrm{Test}}}{A\left(\overline{T_{w, l}}-T_{\text {sat }}\right)}\right|
$$

In equation (6) $A$ is the inner surface area of the test section for the heat transfer length and $T_{\text {sat }}$ is the saturation temperature calculated as the arithmetic mean between the thermocouple measurements at the inlet and outlet of the test section. An uncertainty analysis (Van Rooyen and Christians, 2007) showed that the maximum uncertainty of the average heat transfer coefficient was less than $5 \%$ with the greatest deviations observed at low vapour quality conditions.

$\overline{T_{w, l}}$ is the mean inner-wall temperature of the test section and is related to the mean outer-wall temperature $\overline{T_{w, o}}$ by the thermal resistance of the tube wall $R_{w}$ as:

$$
\overline{T_{w, l}}=\overline{T_{w, o}}+\left|\dot{Q}_{H_{2} O, T e s t} R_{w}\right|
$$

where the thermal resistance of the tube wall was calculated using the tube inner diameter $\left(d_{i}\right)$, tube outer diameter $\left(d_{o}\right)$, tube axial length $(L)$ and tube thermal conductivity $\left(k_{C u}\right)$ as:

$$
R_{w}=\frac{\ln \left(\frac{d_{o}}{d_{i}}\right)}{2 \pi k_{C u} L}
$$

The thermal resistance of the tube wall was found to be negligible and therefore it was assumed that the average wall temperature on the outside of the test section was equal to the average wall 
temperature on the inside of the test section. The mean outer-wall temperature $\left(\overline{T_{w, o}}\right)$ was calculated by averaging the temperature measurements from each of the seven measurement stations $\left(T_{w, o}^{j}\right)$ along the test section using a trapezoidal integration routine as follows:

$$
\overline{T_{w, o}}=\frac{1}{L} \sum_{j=1}^{6}\left[\left(\frac{T_{w, o}^{j}+T_{w, o}^{j+1}}{2}\right)\left(z_{j+1}-z_{j}\right)\right]
$$

In equation $(9) z_{j}$ is the $j$ th temperature measurement station on the test section.

The energy balance $\left(E B_{\text {System }}\right)$, in percentage, was determined by comparing the heat transferred to the water stream in the annulus of the test section $\left(\dot{Q}_{\mathrm{H}_{2} \mathrm{O}}\right)$ to the heat transfer rate rejected by the condensing refrigerant $\left(\dot{Q}_{R}\right)$ in the inner tube as:

$$
E B_{\text {System }}=\left|\frac{\dot{Q}_{R}-\dot{Q}_{\mathrm{H}_{2} \mathrm{O}}}{\left(\dot{Q}_{R}+\dot{Q}_{\mathrm{H}_{2} \mathrm{O}}\right) / 2}\right| \times 100
$$

The mass flux $(G)$ was determined from the measured liquid refrigerant mass flow rate $\left(\dot{m}_{R}\right)$ and tube inner cross sectional flow area $(A)$ as:

$$
G=\frac{\dot{m}_{R}}{A}
$$

Table 1 presents the average, maximum, minimum and standard deviations of the measured experimental parameters at all flow conditions considered during the study. The saturation conditions were controlled with standard deviations of $0.31{ }^{\circ} \mathrm{C}$ and $9.67 \mathrm{kPa}$ for saturation temperature and saturation pressure respectively. The energy balance was controlled within a $1 \%$ standard deviation with an average value of $2.65 \%$ for all experimental conditions. The largest deviation (6\% heat loss to ambient atmosphere) was observed at the lowest mass flux and vapour quality combinations.

Table 1: Summary of statistics for experimental parameters at all flow conditions

\begin{tabular}{|c|c|c|c|c|}
\hline Parameter & Average & Minimum & Maximum & $\begin{array}{c}\text { Standard } \\
\text { deviation }\end{array}$ \\
\hline Saturation temperature & $39.70^{\circ} \mathrm{C}$ & $39.00^{\circ} \mathrm{C}$ & $40.41^{\circ} \mathrm{C}$ & $0.31^{\circ} \mathrm{C}$ \\
\hline Saturation pressure & $1044.36 \mathrm{kPa}$ & $1029.12 \mathrm{kPa}$ & $1073.32 \mathrm{kPa}$ & $9.67 \mathrm{kPa}$ \\
\hline Energy balance & $2.65 \%$ & $6.08 \%$ & $0.46 \%$ & $1.07 \%$ \\
\hline
\end{tabular}




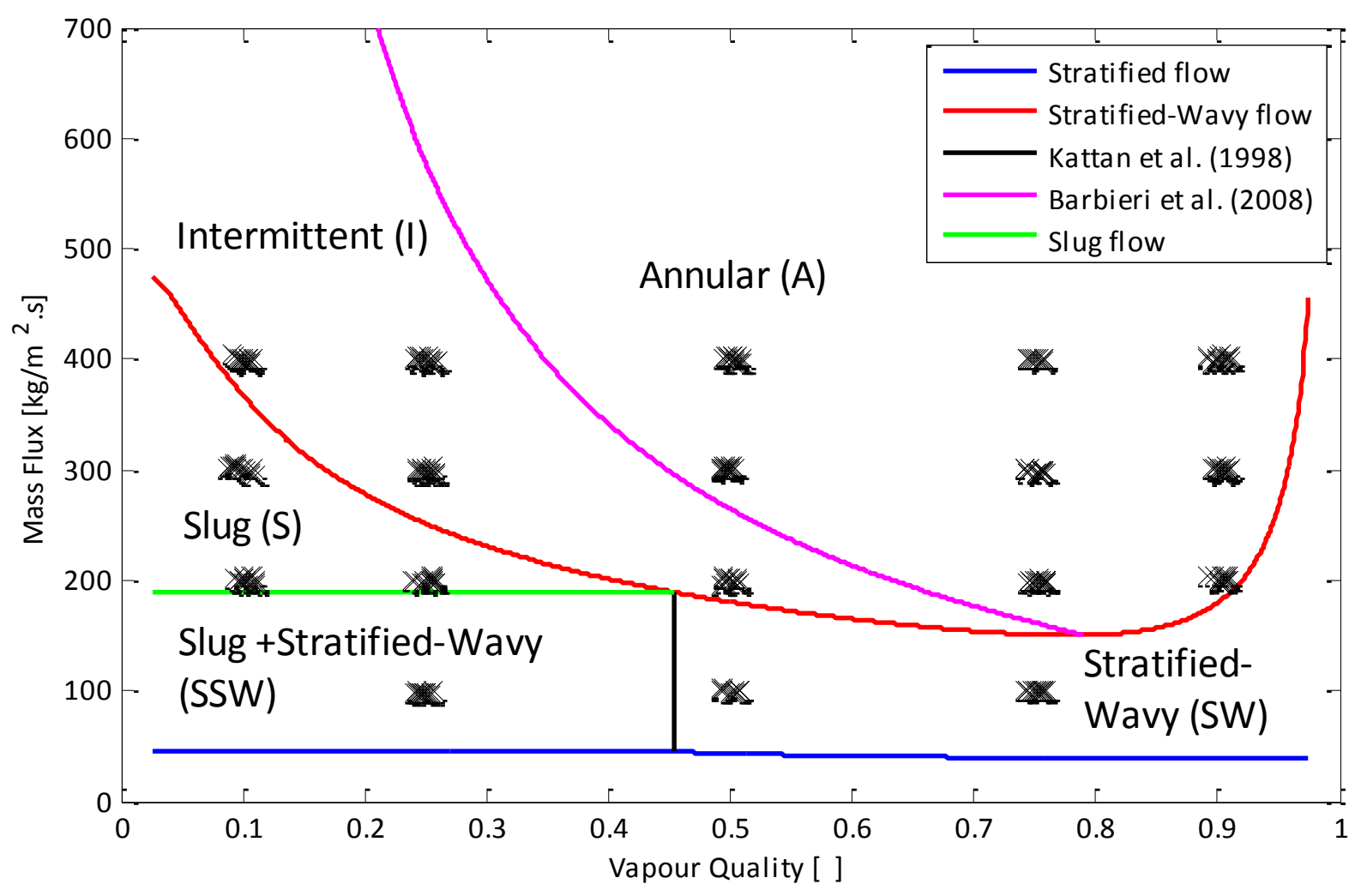

Figure 3: The 360 data points of this study plotted on the modified Wojtan et al. (2005) flow pattern map

As the current study was a follow-up to work carried out in the past the data population was similar (Lips and Meyer, 2012b, 2012c). A lower mass flux case ( $G=100 \mathrm{~kg} / \mathrm{m}^{2} . \mathrm{s}$ ) was included because the effect of inclination angle on two-phase flow was expected to be more profound at lower mass fluxes. The experimental data set consisted of 360 data points in total and the data points are shown in Figure 3. Experiments were conducted at horizontal inclinations $\left(0^{\circ}\right)$, vertical upward inclinations $\left(90^{\circ}\right)$, vertical downward inclinations $\left(-90^{\circ}\right)$ as well as the following intermediate inclination angles: $\pm 5^{\circ}, \pm 10^{\circ}, \pm 15^{\circ}, \pm 20^{\circ}, \pm 30^{\circ}, \pm 45^{\circ}, \pm 60^{\circ}$ and $\pm 75^{\circ}$. The data points are given as function of mass flux, vapour quality and expected flow regime as for a horizontal tube on a modified Wojtan et al. (2005) flow pattern map with the Kattan et al. (1998) and Barbieri et al. (2008) intermittent-annular transition lines. The modified Wojtan et al. (2005) flow pattern map was used throughout the current study for all tube inclinations since it was used during the calibration of the void fraction sensors (De Kerpel et al., 2013). For each data point in Figure 3, measurements were taken at different inclination angles ranging from vertical upward $\left(90^{\circ}\right)$ flow to vertical downward $\left(-90^{\circ}\right)$ flow along with several intermediate inclination angles (see Figure 6 to Figure 11).

For the lowest mass flux $\left(100 \mathrm{~kg} / \mathrm{m}^{2} . \mathrm{s}\right)$, the average vapour quality cases of $10 \%$ and $90 \%$ were omitted from the data set because the inlet fluid state would be superheated or the outlet fluid state would be sub-cooled to obtain the required average vapour quality. The heat transfer results 
for the $90 \%$ vapour quality case at $300 \mathrm{~kg} / \mathrm{m}^{2}$.s were also omitted as it was found to be unstable and not very repeatable (it may have been because the flow regime condition was close to the point where the flow regime changed from annular flow to stratified wavy flow) as shown in Figure 3.

Observations of the flow patterns were made using high-speed video footage. When the observed flow patterns were adjudged to be a combination of two distinct flow types, a system of naming the flow pattern (as abbreviated in Figure 3 and also defined in the nomenclature list) using a backstroke was adopted. The first abbreviation (before the backstroke) was considered the dominant flow pattern with the second abbreviation a significantly contributing secondary flow pattern effect.

\section{Data validation}

The void fraction and heat transfer coefficients were validated by taking measurements for the case of horizontal flow with $200 \mathrm{~W}$ of condensation heat transfer and comparing the results with literature. Figure 4 presents the measured void fractions for horizontal flow plotted against vapour quality at mass fluxes of $100,200,300$ and $400 \mathrm{~kg} / \mathrm{m}^{2}$.s. Additionally, the predictions of the Rouhani and Axelsson (1970) correlation as well as the prevailing observed flow patterns are also presented. The flow patterns are compared with the flow pattern map of Figure 3.

In general the horizontal void fraction results correlated well with predictions; all void fraction measurements were predicted within $\pm 5 \%$. The degree of correlation was observed to reduce with decreasing vapour quality. The aforementioned observation was not unexpected due to the highly non-linear nature of the Rouhani and Axelsson (1970) in this region of vapour quality. Five observed data points out of a total of 18 data points (a total of 18 unique flow conditions with two successive measurements taken for each respective flow condition resulting in a total of 36 data points) did not match the predictions of the modified Wojtan et al. (2005) flow pattern map (Figure 4). The aforementioned exceptions could be isolated to the predictions of intermittent flow, which were difficult to classify using subjective visual means.

In Figure 5, the measured heat transfer coefficients are compared with predictions. The comparisons were made using the Thome et al. (2003) heat transfer correlation using their prescribed logarithmic mean void fraction model as well as the experimentally measured void fractions of this study. Comparisons were also made with the Thome et al. (2003) correlation making use of the Woldesemayat and Ghajar (2007) void fraction predictions and the Cavallini et al. (2006) heat transfer correlation. 


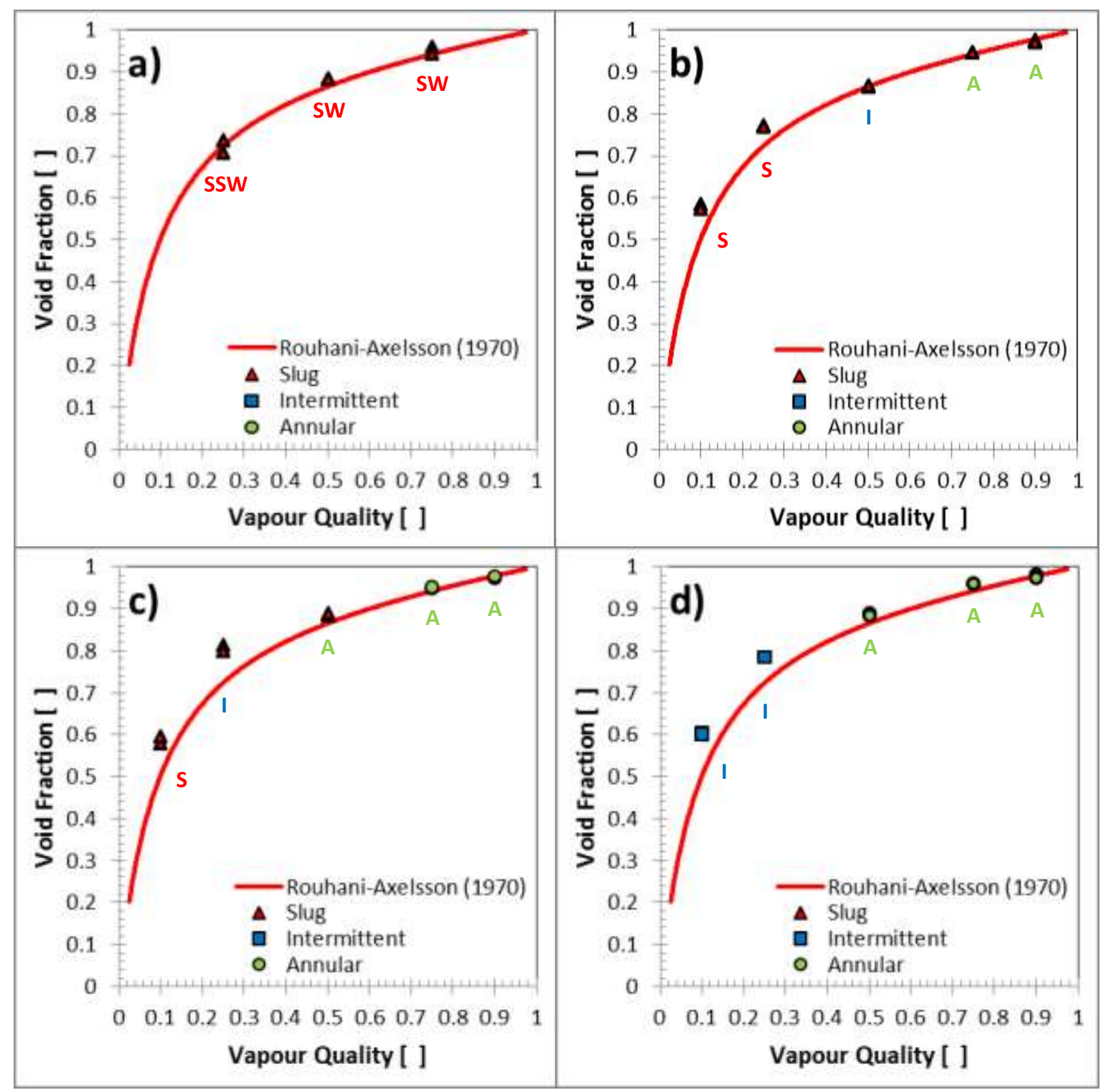

Figure 4: Experimental void fraction measurements as a function of average vapour quality compared with the predictions of the Rouhani and Axelsson (1970) void fraction correlation for the case of a horizontal tube for mass fluxes of a) $100 \mathrm{~kg}-\mathrm{m}^{2} . \mathrm{s}$, b) $200 \mathrm{~kg}-\mathrm{m}^{2} . \mathrm{s}$, c) $300 \mathrm{~kg}-\mathrm{m}^{2} . \mathrm{s}$ and d) $400 \mathrm{~kg}-\mathrm{m}^{2} . \mathrm{s}$. The prevailing flow pattern as observed is indicated by the symbols in the legend. At each data point, the flow pattern predicted by the modified Wojtan et al. (2005) flow pattern map is indicated using the following abbreviations: Slug (S), stratified-wavy (SW), slug and stratified-Wavy (SSW), intermittent (I) and annular (A). The colour-coding of the abbreviations also correlates with the flow classification of De Kerpel et al. (2013) in the legend.

For horizontal flows, $67 \%$ of the heat transfer coefficients (a total of 18 unique flow conditions with two successive measurements taken for each respective flow condition resulting in a total of 36 data points) were predicted within a $\pm 10 \%$ error by the Thome et al. (2003) correlation. At low values of 


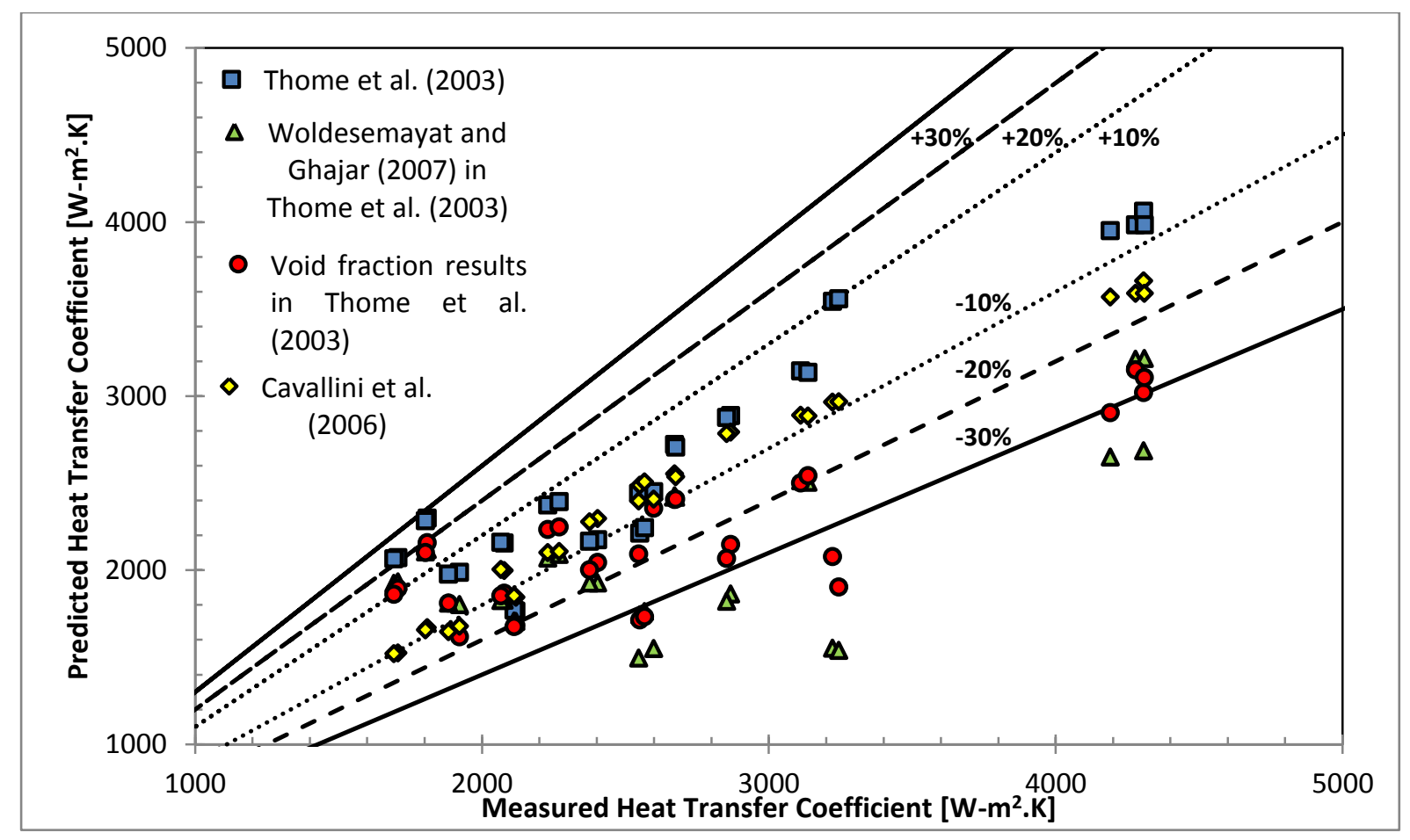

Figure 5: Experimental heat transfer coefficients for the case of horizontal flow compared with the correlations of Thome et al. (2003) and Cavallini et al. (2006). Also included are the comparisons with the Thome et al. (2003) heat transfer correlation with the void fraction (VF) model replaced with the correlation of Woldesemayat and Ghajar (2007) and the experimentally measured void fraction results.

heat transfer coefficient conditions, i.e. low mass flux and vapour quality, the Thome et al. (2003) correlation over-predicted the experimental results by about 20-30\%. The heat transfer predictions exhibited scatter; this could be the result of the Thome et al. (2003) correlation's dependence on the void fraction, which varied with the flow configuration.

The substitution of the void fraction parameter with the experimental void fractions did not seem to improve the prediction accuracy of the Thome et al. (2003) correlation, especially at conditions of higher heat transfer. A sensitivity analysis using the Thome et al. (2003) correlation revealed that, especially for high vapour quality cases, the predicted heat transfer coefficient was very sensitive to variations of the void fraction parameter. In certain cases, the predicted heat transfer coefficients varied by $10 \%$ with miniscule changes (less than $1 \%$ ) to the void fraction parameter. Thus, any small deviations in the void fraction measurements compared with the predicted values amplified the deviations observed in predicted heat transfer coefficient.

The general trend was that the data points were under-predicted using this method; a number of data points were under-predicted by more than $20 \%$. A similar trend was observed when the void fraction parameter was substituted for the predictions of the Woldesemayat and Ghajar (2007) void 
fraction correlation. Subsequently, this method did not produce acceptable heat transfer predictions as many data points were not predicted within a $\pm 30 \%$ error band.

The Cavallini et al. (2006) heat transfer correlation correlated the results well with the majority of the data points predicted within a $\pm 10 \%$ error. At the higher heat transfer conditions, i.e. higher mass flux and vapour quality, the results were under-predicted, but still fell within a $\pm 20 \%$ error band. The heat transfer predictions of the Cavallini et al. (2006) correlation did not exhibit as much scatter throughout the data set. This may be a result of the Cavallini et al. (2006) correlation's independence of the void fraction. The accuracy of the Thome et al. (2003) heat transfer correlation, however, is directly dependent on the value of the void fraction. Therefore, if the void fraction can be determined with greater accuracy the heat transfer coefficients can also be estimated with greater accuracy.

The measured heat transfer coefficients were also compared with the measured heat transfer coefficients of Lips and Meyer (2012b) who used the same experimental set-up. In the previous study the thermocouples were calibrated against a PT100 before soldering them to the test section. However, in this study the thermocouples were calibrated against a PT100 during adiabatic conditions after the thermocouples were soldered to the test section. The calibration technique used in this study should be more accurate than in the previous study and could explain the difference in results.

Therefore, the absolute values of the heat transfer coefficients for the current study were greater than those found in the study of Lips and Meyer (2012b). For the reference case of $300 \mathrm{~kg} / \mathrm{m}^{2} . \mathrm{s}$ mass flux, the measured heat transfer coefficients were an average of $17 \%$ greater than those of Lips and Meyer (2012b) with the discrepancies increasing with increased vapour quality (32\% maximum deviation observed at $75 \%$ vapour quality). Similarly, for the case of varying mass flux $\left(200 \mathrm{~kg} / \mathrm{m}^{2} . \mathrm{s}\right.$ to $400 \mathrm{~kg} / \mathrm{m}^{2} . \mathrm{s}$ ) at a constant vapour quality of $50 \%$, the measured heat transfer coefficients were an average of $26 \%$ greater than those obtained during the study of Lips and Meyer (2012b) with a maximum deviation of $39 \%$ observed at $400 \mathrm{~kg} / \mathrm{m}^{2} . s$ mass flux. The discrepancies were observed to increase with increasing mass flux and were confirmed by several repeated measurements. The deviations in heat transfer coefficient relative to those of the Lips and Meyer (2012b) study were relatively constant for each mass flux and vapour quality combination for all inclination angles, which seemed to indicate that the deviations could be purely a result of the more rigorous in-situ thermocouple calibration technique which was employed for the current study. Furthermore, the repeatability of all the measurements were constantly monitored throughout the study by taking repeated measurements at horizontal flow conditions for each mass flux and vapour quality case. 
For each case the successive measurements at horizontal flow were not significantly different and repeatability was therefore confirmed.

\section{Effect of inclination angle, vapour quality and mass flux on void fraction and heat transfer}

The experimentally observed influence of tube inclination angle, vapour quality and mass flux on the measured void fractions and heat transfer coefficients are discussed in this section. Since the effect of inclination angle was most pronounced at lower mass flux and vapour quality combinations, these flow conditions will receive more detailed discussions. The flow pattern classifications in terms of physical structure used in determining the void fraction measurements i.e. slug flow, intermittent flow and annular flow were done according to previous work conducted using the same flow pattern classification in terms of physical structure than De Kerpel et al. (2013) and Thome (2006).

\subsection{Mass flux of $100 \mathrm{~kg} / \mathrm{m}^{2} . \mathrm{s}$}

The measured void fractions for the $100 \mathrm{~kg} / \mathrm{m}^{2}$.s case varied significantly from horizontal flow $\left(0^{\circ}\right.$ inclination angle) at $25 \%$ vapour quality, even for small adjustments in the inclination angle (Figure 6). The effect of inclination angle on the measured void fractions decreased with increasing vapour quality with the measured void fractions being almost independent of inclination angle for the $75 \%$ vapour quality case. The measured void fractions were observed to increase with increasing downward inclination (negative inclination angles) up to a maximum at vertical downward flow. The increase in the measured void fraction could be explained by observing the prevalence of stratifiedtype flow with the characteristic thin liquid layer as a result of gravity-dominated flow. The void fraction sensors were very sensitive to changes in capacitance of the flow, but their response was also non-linear and dependent on the spatial distribution of liquid and vapour phases between the sensing electrodes. The very slight increase in void fraction observed at $-90^{\circ}$ could therefore be a result of the redistribution of the liquid-vapour phases around the periphery of the tube and not necessarily an increase in the void fraction.

The measured void fractions decreased by $35 \%$ compared with horizontal flow for increased upward inclinations (positive inclination angles) up to an inclination of $30^{\circ}$ for $25 \%$ vapour quality. A similar trend was observed for $50 \%$ vapour quality albeit with less profound difference from horizontal flow. The decrease in measured void fractions could be explained by observing the prevailing flow patterns i.e. churn-type flows with liquid recirculation. The greatest degree of recirculating flow corresponded to the minimum measured void fraction. Even though the liquid-vapour distribution 

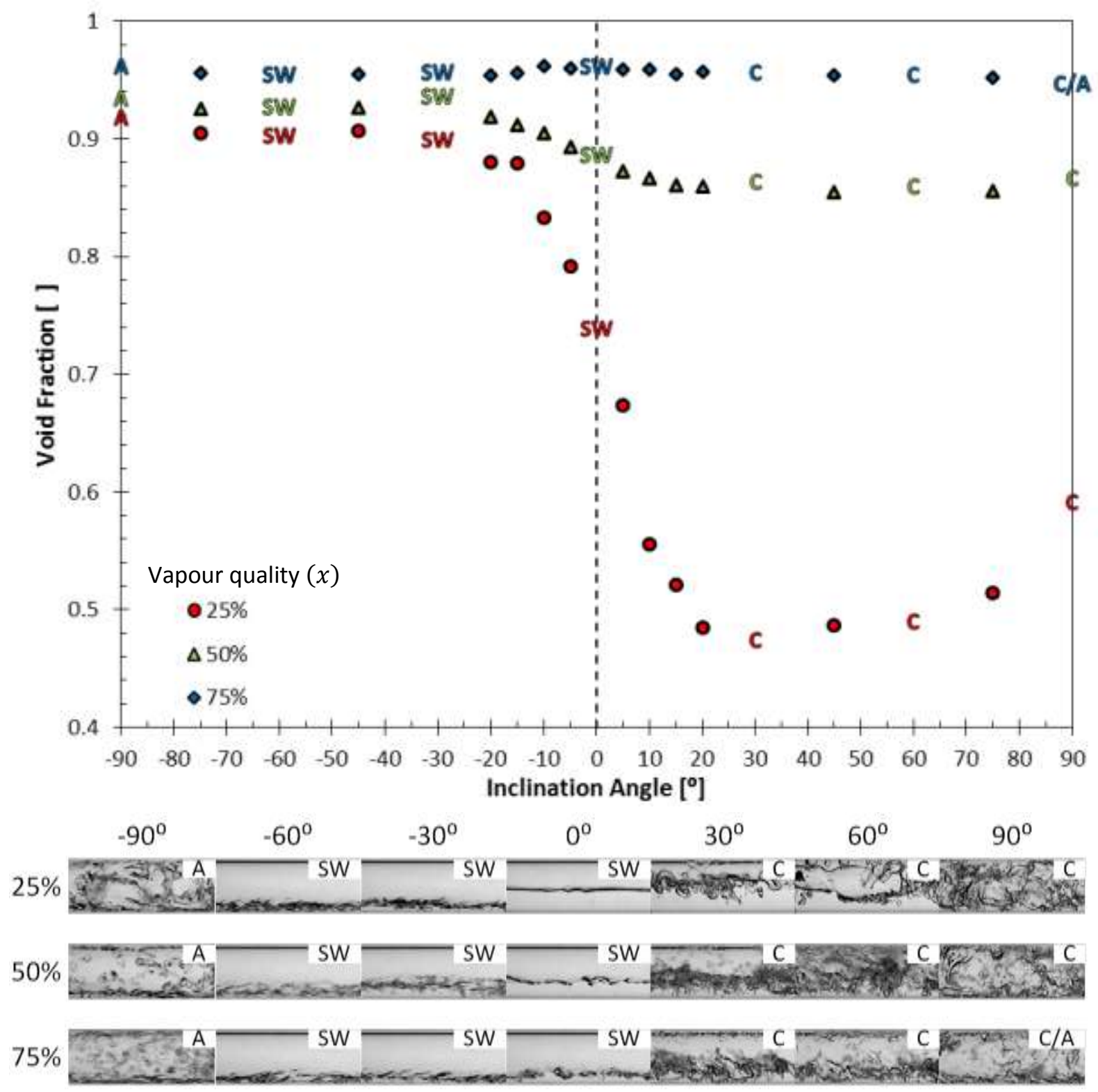

Figure 6: Void fractions as function of test section inclination angle for a mass flux of $G=100 \mathrm{~kg}-\mathrm{m}^{2} . \mathrm{s}$ and

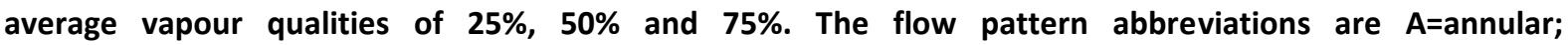
$S W=$ stratified-wavy; $C=$ churn.

was observed to change for the $75 \%$ vapour quality case, the measurements indicated that the void fraction remained relatively constant for all inclination angles. From the experimental observations, it could be deduced that the void fractions for inclined flows were dominated by the liquid phase as a result of its greater density and the accompanying greater effect of gravity. It appeared that the vapour phase distribution merely adapted to that of the liquid phase at the low mass flux of $100 \mathrm{~kg} / \mathrm{m}^{2}$.s. At higher mass fluxes (section 5.2 and 5.3) it seemed as if the vapour phase movement relative to that of the liquid phase may become significant due to interfacial shear effects. 
The observed flow patterns corresponded with the predictions of the flow pattern map i.e. stratified-wavy type flow. In general, the void fractions and flow patterns were not predicted satisfactorily for the current case of low vapour quality and low mass flux flow conditions at upward inclinations.

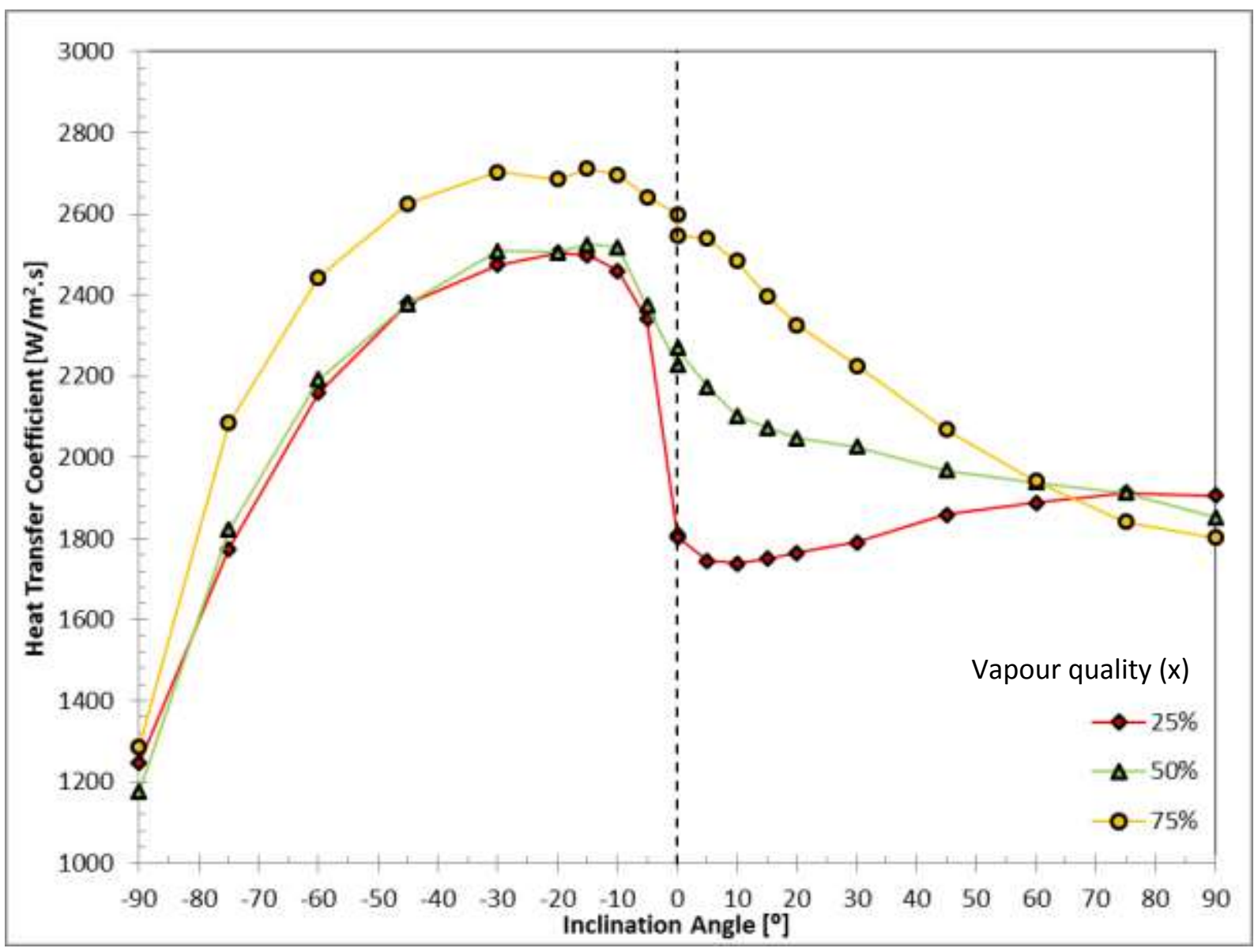

Figure 7: Heat transfer coefficients as a function of inclination angle for a mass flux of $\mathbf{G}=\mathbf{1 0 0} \mathbf{~ k g}$ $\mathrm{m}^{2}$. and average vapour qualities of $x=25 \%, x=50 \%$ and $x=75 \%$.

The heat transfer coefficients (Figure 7) were observed to increase significantly with increasing downward inclination up to a maximum in the region of $-20^{\circ}$ to $-15^{\circ}$; a $38 \%$ increase relative to horizontal flow was observed for the $25 \%$ vapour quality case. The maximum heat transfer coefficients were observed at downward inclination angles where void fractions increased significantly. At these inclination angles, therefore, the thermal resistance was a minimum, i.e. the liquid film thickness was at a minimum as a result of the liquid layer that not only flowed from the top of the tube radially downward, but also forward in the direction of the fluid flow. Further increases in the downward inclination of the flow decreased the measured heat transfer coefficients considerably. Minimum heat transfer was observed at vertical downward flows e.g. a 50\% reduction compared with the case of horizontal flow for $75 \%$ vapour quality. For vertical downward flows, the 
thermal resistance was increased exclusively by changes in flow pattern for $50 \%$ and $75 \%$ vapour quality since the measured void fractions remained relatively constant. The increase in thermal resistance at vertical downward tube inclination could be the result of the redistribution of the liquid phase to the periphery of the tube resulting in a net increase in liquid layer thickness, resulting in reduced heat transfer coefficients.

For the $25 \%$ vapour quality case, increases in upward inclination angle (past the observed minimum at $10^{\circ}$ inclination) increased the measured heat transfer coefficients compared to the case of horizontal inclination. The aforementioned increase in heat transfer relative to the horizontal inclination case could have been the result of the more profound recirculating liquid layer decreasing the net thermal resistance through greater mixing. The increase in heat transfer also corroborated with an increase in the measured void fractions for the same inclination angles and hence the reduction in thermal resistance could also be the result of the liquid-vapour redistribution resulting in a net decrease of the liquid film thickness.

For the case of $75 \%$ vapour quality, the heat transfer coefficients were observed to decrease relative to the horizontal flow case with increased upward inclination angle. A 30\% reduction compared with the horizontal case was observed at vertical upward inclination. The measured void fractions were observed to be relatively independent to inclination angle at these flow conditions. Hence, the decrease in measured heat transfer coefficients could have been purely as a result of liquid-vapour redistribution increasing the net thermal resistance. At this relatively high vapour quality $(75 \%)$ the fluid mixing was also not as profound as for the lower vapour quality (25\%), which could also explain the reduction in heat transfer coefficients.

\subsection{Mass flux of $200 \mathrm{~kg} / \mathrm{m}^{2} . \mathrm{s}$}

The measured void fractions were significantly affected by inclination angle compared to horizontal flow for a mass flux of $200 \mathrm{~kg} / \mathrm{m}^{2} . \mathrm{s}$ (Figure 8). For example, a 39\% increase compared with horizontal flow was observed at a downward inclination angle of $-45^{\circ}$ for the case of $10 \%$ vapour quality. The increase in measured void fractions could be put down to a change in the two-phase flow structure i.e. the preferential redistribution of the liquid phase to the bottom of the tube under the influence of gravity. The aforementioned redistribution resulted in a thinner liquid layer congregating at the bottom of the tube which in turn resulted in a decrease in void measured fraction. The effect of inclination angle on the measured void fractions deteriorated with increasing vapour quality. Similar 


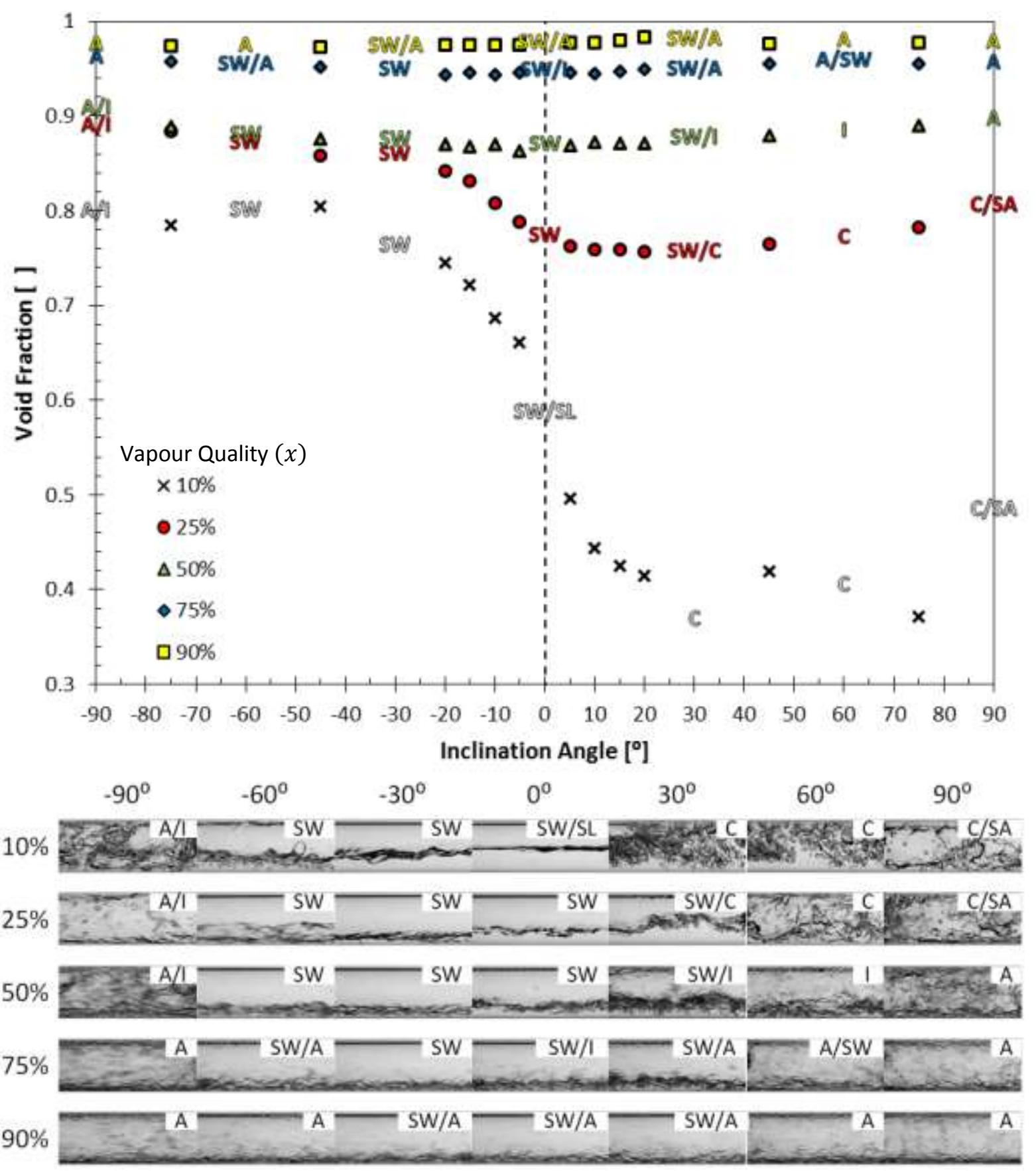

Figure 8: Void fractions as a function of test section inclination angle for a mass flux of $\mathbf{G}=\mathbf{2 0 0} \mathbf{~ k g}$ $\mathrm{m}^{2} . \mathrm{s}$ and average vapour qualities of $10 \%, 25 \%, 50 \%, 75 \%$ and $90 \%$. The flow pattern abbreviations are $A=$ =annular; SW=stratified-wavy; $C=$ churn; I=intermittent; $S L=s l u g ; S A=s e m i-a n n u l a r$.

trends were observed for the lower vapour quality cases (10\% and $25 \%)$ while relative independence towards inclination angle was observed for the higher vapour quality cases (50\%, $75 \%$ and $90 \%)$.

Similar to the $100 \mathrm{~kg} / \mathrm{m}^{2}$.s mass flux case, the measured void fractions decreased with increasing upward inclination angles, albeit to a lesser degree. The most profound decrease in measured void fractions was observed at an upward inclination angle of $30^{\circ}$ for both the $10 \%$ and $25 \%$ vapour 
quality cases; a $37 \%$ and $20 \%$ decrease relative to the horizontal case was observed respectively. The reduction in measured void fractions could again be put down to the prevalence of recirculating liquid slugs in the flow. The suppressed inclination effect for the $25 \%$ vapour quality case could be the result of increased vapour shear velocity accompanying an increase in mass flux. Further increases in upward inclination angle led to increases in measured void fraction for the lower vapour qualities up to vertical upward flow; the scatter in the results could be a result of the highly chaotic churn-type flow that prevailed. An analysis of the raw voltage signal which illustrates how chaotic the flow structures of horizontal two-phase flow (which is merely slug-type flow and not recirculating churn-type flow) can be, is found in literature (Canière et al., 2007). Our measured raw signals compared well with the signals of the aforementioned study. The higher vapour quality conditions (50\%, $75 \%$ and $90 \%)$ again exhibited independence towards the effect of inclination angle.

Again, the observed flow patterns did not correlate well with the predictions of the modified Wojtan et al. (2005) flow pattern map since only churn-type flows with liquid recirculation were observed for lower vapour qualities at upward inclinations. The flow pattern predictions resembled the observed flow patterns more closely for downward flows i.e. slug-type flow was predicted and stratified-wavy flow was observed.

The heat transfer coefficients for the full range of tube inclinations clearly illustrate the tendency of decreased dependence on inclination angle with increased vapour quality (Figure 9). All vapour quality cases exhibited a maximum heat transfer coefficient in the vicinity of $-20^{\circ}$ downward inclination e.g. maximum increases of $44 \%$ and $18 \%$ were observed compared to horizontal flow for lower vapour qualities (10\% and $25 \%$ ). The relative effect of downward inclination angle diminished with increasing vapour quality. The tube inclinations at which maximum heat transfer was observed did not correlate directly with the maximum void fraction measurements. Thus, conditions of minimal thermal resistance did not correspond to conditions of minimum liquid phase as expected. Other flow phenomena such as liquid-vapour distribution and mixing could therefore be assumed dominant for heat transfer at the flow conditions currently under consideration. Further increases in downward inclination led to reductions in the measured heat transfer coefficients up to minima observed at vertical downward flow for all vapour qualities barring the $90 \%$ case. 


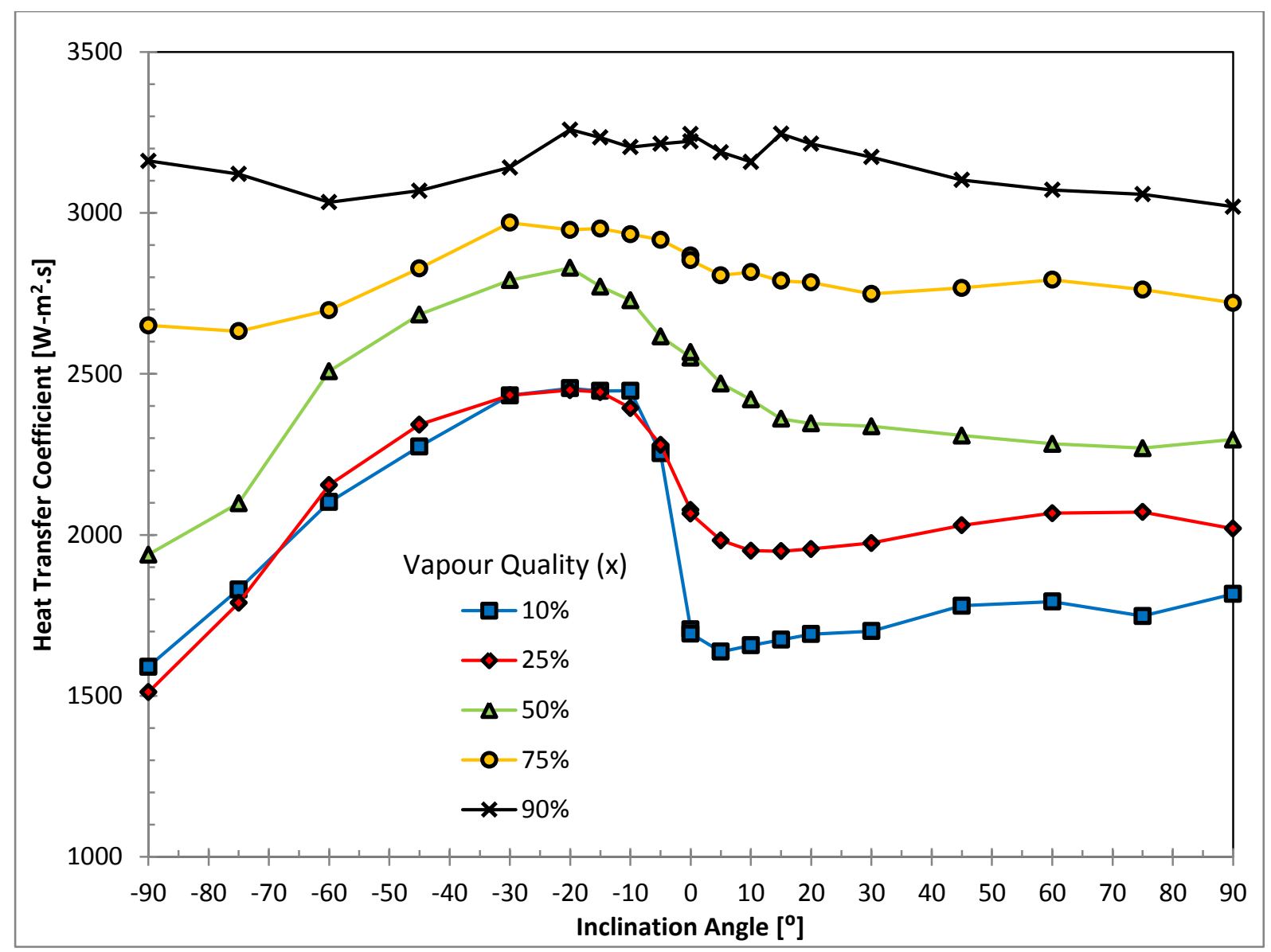

Figure 9: Heat transfer coefficients as a function of inclination angle for a mass flux of $\mathbf{G}=\mathbf{2 0 0} \mathbf{~ k g}$ $\mathrm{m}^{2}$. and average vapour qualities of $x=10 \%, x=25 \%, x=50 \%, x=75 \%$ and $x=90 \%$.

As before, heat transfer coefficients were observed to decrease at upward flows close to the horizontal for low vapour qualities (10\% and $25 \%)$. The upward inclination effect progressively smoothed out with increased vapour quality. Further increases in upward inclination angle resulted in increased heat transfer coefficients relative to the minimum values which could be explained using the observed flow patterns. For increasing upward inclination, churn-type flow patterns were observed, but with the liquid layer distributed relatively thinly and evenly around the periphery of the tube, i.e. annular flow tendencies with reduced thermal resistance.

\subsection{Mass flux of $300 \mathrm{~kg} / \mathrm{m}^{2} . \mathrm{s}$}

As in section 5.2, the measured void fractions were observed to increase with increasing downward inclination angle with maximum values obtained at vertical downward flow for all vapour qualities (Figure 10). However, the effect of inclination angle is suppressed by the greater mass flux with only the $10 \%$ vapour quality case exhibiting an S-type curve similar to lower mass flux conditions; a $28 \%$ increase in measured void fraction was observed for the $10 \%$ vapour quality case at vertical downward flow. For increasing upward inclination angle, only the $10 \%$ vapour quality case exhibited 


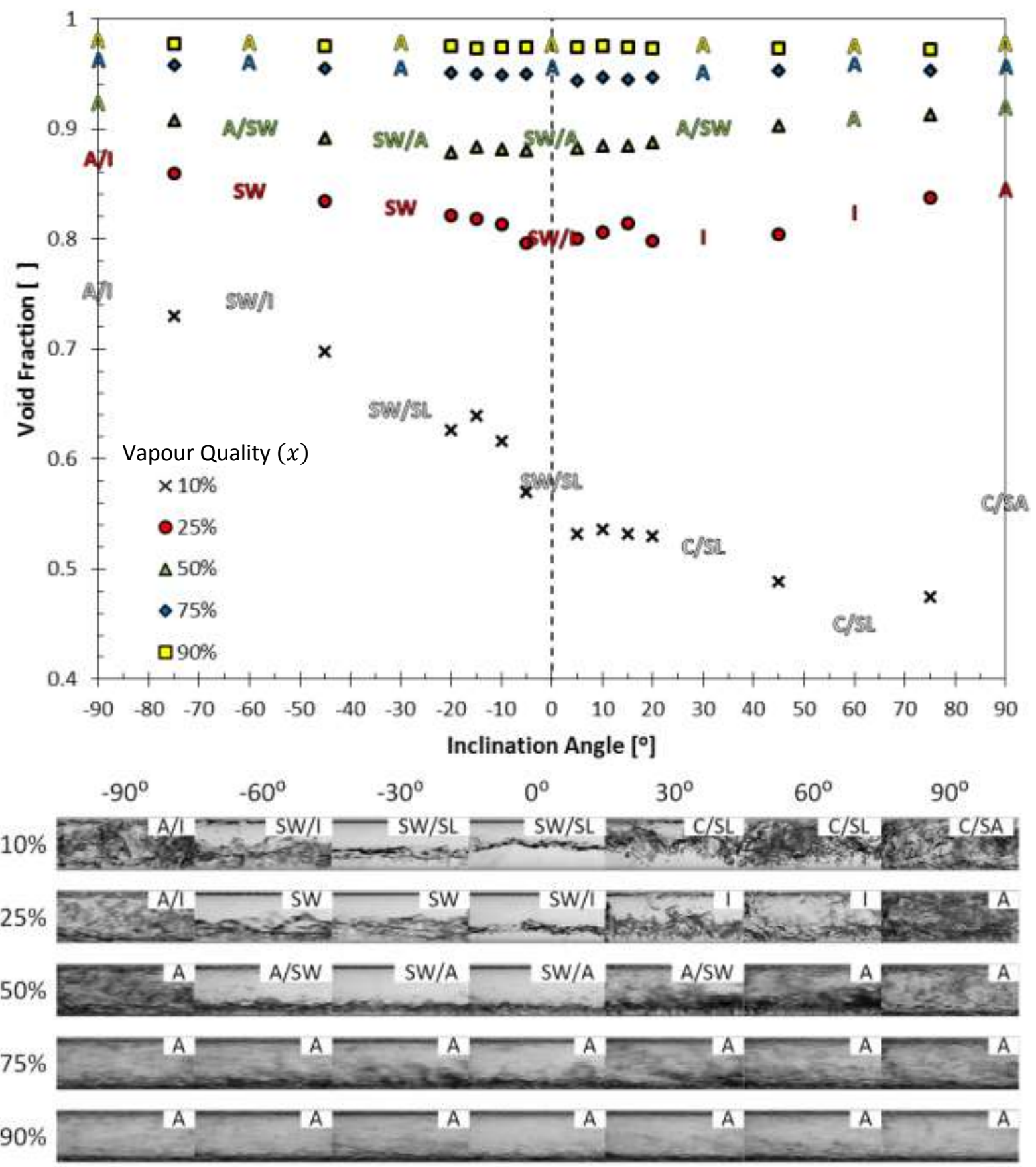

Figure 10: Void fractions as function of test section inclination angle for a mass flux of $\mathbf{G}=\mathbf{3 0 0} \mathbf{~ k g}$ $\mathrm{m}^{2} . \mathrm{s}$ and average vapour qualities of $10 \%, 25 \%, 50 \%, 75 \%$ and $90 \%$. The flow pattern abbreviations are $A=$ =annular; SW=stratified-wavy; $C=$ churn; I=intermittent; $S L=s l u g ; S A=s e m i-a n n u l a r$.

significant reduction in measured void fractions with a $24 \%$ reduction observed at $60^{\circ}$ upward inclination compared to horizontal flow. A maximum deviation of $9 \%$ compared to horizontal flow was observed in measured void fractions for the $25 \%$ vapour quality case. All other vapour qualities could be considered independent of inclination angle since the vapour shear velocity at the current mass flux was sufficient to maintain a constant liquid-vapour distribution. 
The observed flow patterns did not correlate well with the predictions by the modified Wojtan et al. (2005) flow pattern map at low vapour quality conditions (10\% and $25 \%$ ) for all flow inclinations barring the horizontal case. The liquid recirculation was, however, less profound than for the lower mass flux cases with the greater vapour shear velocity being able to carry the liquid slugs against gravity which may account for the relative independence of void fraction measurements to inclination angle. The observed flow patterns were more accurately predicted by the modified Wojtan et al. (2005) flow pattern map for higher vapour quality conditions i.e. 50\%, $75 \%$ and $90 \%$ vapour quality conditions.

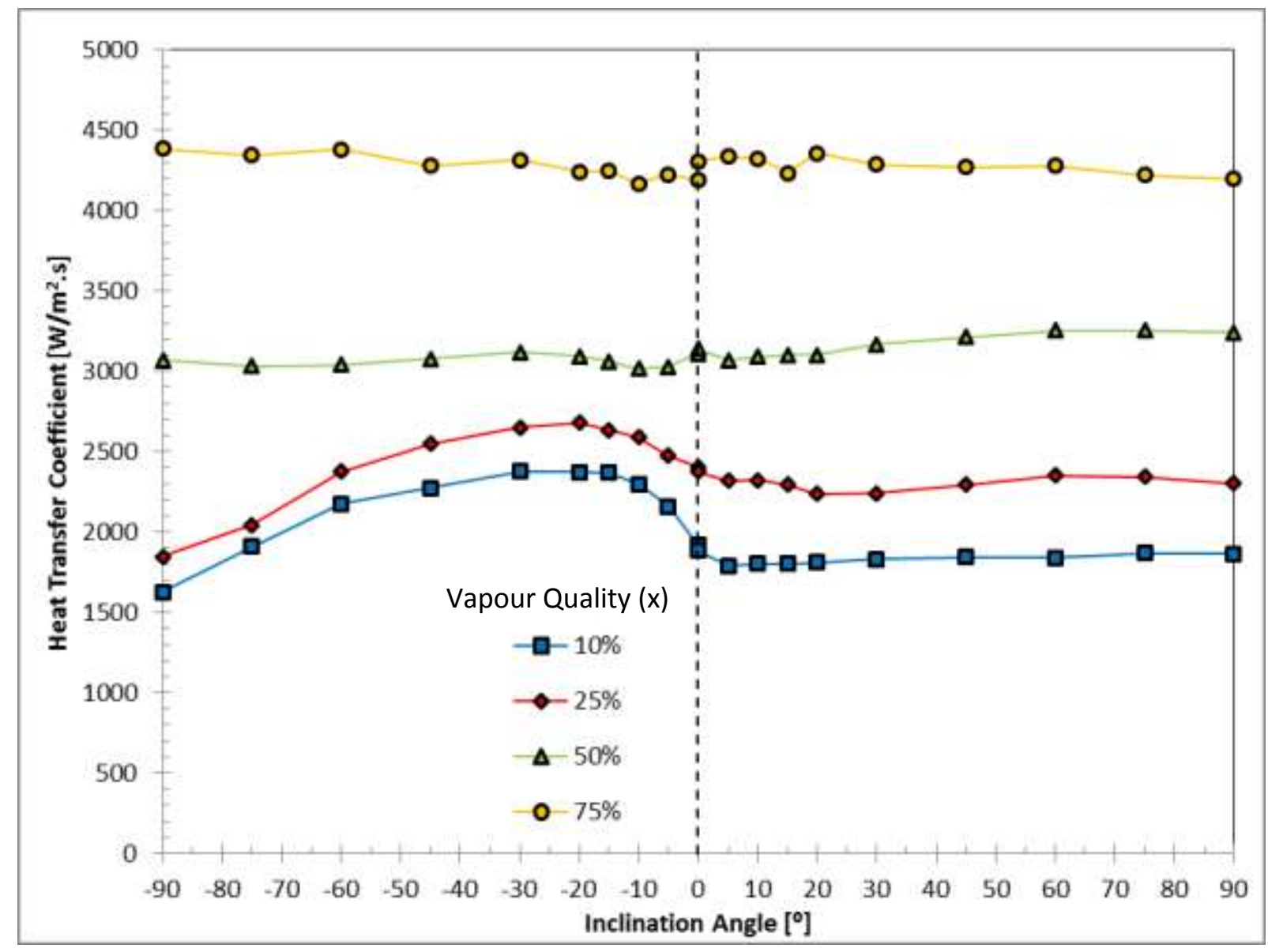

Figure 11: Heat transfer coefficients as a function of inclination angle for a mass flux of $\mathbf{G}=\mathbf{3 0 0} \mathbf{~ k g}$ $\mathrm{m}^{2} . \mathrm{s}$ and average vapour qualities of $x=10 \%, x=25 \%, x=50 \%$ and $x=75 \%$.

For lower vapour quality conditions ( $10 \%$ and $25 \%)$ significant variations in heat transfer coefficients with increasing downward inclination angles were observed (Figure 11). The heat transfer coefficients were observed to increase up to a maximum in the region of $-20^{\circ}$ to $-30^{\circ}$ downward inclination angle for both $10 \%$ and $25 \%$ vapour quality cases; $25 \%$ and $12 \%$ increases relative to horizontal flow respectively. Further increases in downward inclination angle resulted in decreased heat transfer coefficients up to a minimum at vertical downward flow similar to observations made 
for lower mass flux cases. The effect of upward inclination angle was subdued compared with the effect of downward inclinations for lower vapour qualities with only slight variations in the measured heat transfer coefficients observed; maximum deviation from horizontal case was observed as $6 \%$. For higher vapour quality cases $(50 \%$ and $75 \%)$ the measured heat transfer coefficients were hardly affected by changes in inclination angle with only slight variations observed.

\section{Conclusions}

The purpose of this study was to measure void fractions of refrigerant R134a condensing in a smooth circular tube with an inner diameter of $8.38 \mathrm{~mm}$ and a heat transfer length of $1.488 \mathrm{~m}$. Flow regimes were captured, heat transfer measurements were conducted and void fractions were measured with capacitive void fraction sensors at the inlet and outlet of the test section. The average of the two void fractions was used as the average void fraction of the test section. Measurements were conducted for a full spectrum of inclination angles ranging from vertical downward $\left(-90^{\circ}\right)$ to vertical upward $\left(90^{\circ}\right)$ flow. The void fraction measurements were compared to heat transfer coefficients for various mass fluxes ranging from $100-400 \mathrm{~kg} / \mathrm{m}^{2} . \mathrm{s}$ at vapour qualities ranging from $10-90 \%$ with $200 \mathrm{~W}$ of condensation heat transfer.

A general independence towards the effect of inclination angle on measured void fractions and heat transfer coefficients was observed with increasing mass flux and vapour quality. The greatest effect of inclination angle on void fractions and heat transfer coefficients were observed for combinations of low mass flux and vapour quality.

Results at downward flow inclinations were affected more profoundly than for upward inclinations. An optimisation opportunity for heat transfer in low vapour quality flows was also identified. The void fraction and flow pattern map predictions were found to be inadequate for inclined flow conditions and scope exists to incorporate gravity-effects in the aforementioned prediction tools.

\section{Acknowledgements}

The funding obtained from the NRF, TESP, University of Stellenbosch/ University of Pretoria, SANERI/SANEDI, CSIR, EEDSM Hub and NAC is acknowledged and duly appreciated. The University of Ghent is thanked for providing two void fraction sensors.

This study was conducted as a master's degree by the first author under supervision of the second author. The void fraction sensors were provided by the third author and the third and fourth authors who assisted with the implementation of the operational and calibration aspects of the sensor. 


\section{References}

Adelaja, A.O., Dirker, J., Meyer, J.P., 2014a. Convective condensation heat transfer of R134a in tubes at different inclination angles. Int. J. Green Energy.

Adelaja, A.O., Dirker, J., Meyer, J.P., 2014b. Experimental studies of condensation heat transfer in an inclined microfin tube, in: Proceedings of the 15th International Heat Transfer Conference, Kyoto, Paper IHTC 9361. Kyoto.

Ahmed, W.H., 2011. Experimental investigation of air-oil slug flow using capacitance probes, hot-film anemometer, and image processing. Int. J. Multiph. Flow 37, 876-887.

Barbieri, P.E.L., Jabardo, J.M.S., Bandarra Filho, E.P., 2008. Flow Patterns in Convective Boiling of Refrigerant R134a in Smooth Tubes of Several Diameters, in: 5th European Thermal-Sciences Conference. The Netherlands.

Canière, H., Bauwens, B., T'Joen, C., De Paepe, M., 2010. Mapping of Horizontal Refrigerant Two-Phase Flow Patterns Based on Clustering of Capacitive Sensor Signals. Int. J. Heat Mass Transf. 53, 5298-5307.

Canière, H., Bauwens, B., T’Joen, C., De Paepe, M., 2009. Probabilistic Mapping of Adiabatic Horizontal TwoPhase Flow by Capacitance Signal Feature Clustering. Int. J. Multiph. Flow 35, 650-660.

Canière, H., T’Joen, C., Willockx, A., De Paepe, M., 2008. Capacitance Signal Analysis of Horizontal Two-Phase Flow in a Small Diameter Tube. Exp. Therm. Fluid Sci. 32, 892-904.

Canière, H., T'Joen, C., Willockx, A., De Paepe, M., Christians, M., Van Rooyen, E., Liebenberg, L., Meyer, J.P., 2007. Horizontal Two-Phase Flow Characterization for Small Diameter Tubes with a Capacitance Sensor. Meas. Sci. Technol. 18, 2898-2906.

Cavallini, A., Del Col, D., Doretti, L., Matkovic, M., Rossetto, L., Zilio, C., Censi, G., 2006. Condensation in Horizontal Smooth Tubes: A New Heat Transfer Model for Heat Exchanger Design. Heat Transf. Eng. 27, 31-38.

Da Riva, E., Del Col, D., Garimella, S. V., Cavallini, A., 2012. The Importance of Turbulence During Condensation in a Horizontal Circular Minichannel. Int. J. Heat Mass Transf. 55, 3470-3481.

Da Silva, M.J., Thiele, S., Abdulkareem, L., Azzopardi, B.J., Hampel, U., 2010. High-Resolution Gas-Oil TwoPhase Flow Visualization with a Capacitance Wire-Mesh Sensor. Flow Meas. Instrum. 21, 191-197.

De Kerpel, K., Ameel, B., De Schampheleire, S., T'Joen, C., Canière, H., De Paepe, M., 2014. Calibration of a capacitive void fraction sensor for small diameter tubes based on capacitive signal features. Appl. Therm. Eng. 63, 77-83.

De Kerpel, K., Ameel, B., T’Joen, C., Canière, H., De Paepe, M., 2013. Flow Regime Based Calibration of a Capacitive Void Fraction Sensor for Small Diameter Tubes. Int. J. Refrig. 36, 390-401.

Demori, M., Ferrari, V., Strazza, D., Poesio, P., 2010. A Capacitive Sensor System for the Analysis of Two-Phase Flows of Oil and Conductive Water. Sensors Actuators A Phys. 163, 172-179.

Doretti, L., Zilio, C., Mancin, S., Cavallini, A., 2013. Condensation flow patterns inside plain and microfin tubes: A review. Int. J. Refrig. 36, 567-587. 
Dos Reis, E., Goldstein, L., 2005. A Procedure for Correcting for the Effect of Fluid Flow Temperature Variation on the Response of Capacitive Void Fraction Meters. Flow Meas. Instrum. 16, 267-274.

El Hajal, J., Thome, J.R., Cavallini, A., 2003. Condensation in Horizontal Tubes, Part1: Two-phase Flow Pattern Map. Int. J. Heat Mass Transf. 46, 3349-3363.

Kattan, N., Thome, J.R., Favrat, D., 1998. Flow Boiling in Horizontal Tubes. Part 3: Development of a New Heat Transfer Model Based on Flow Patterns. J. Heat Transfer 120, 156-165.

Lips, S., Meyer, J., 2012a. Stratified Flow Model for Convective Condensation in an Inclined Tube. Int. J. Heat Fluid Flow 36, 83-91.

Lips, S., Meyer, J.P., 2012b. Experimental Study of Convective Condensation in an Inclined Smooth Tube. Part I: Inclination Effect on Flow Pattern and Heat Transfer Coefficient. Int. J. Heat Mass Transf. 55, 395-404.

Lips, S., Meyer, J.P., 2012c. Experimental Study of Convective Condensation in an Inclined Smooth Tube. Part II: Inclination Effect on Pressure Drops and Void Fractions. Int. J. Heat Mass Transf. 55, 405-412.

Lips, S., Meyer, J.P., 2011. Two-Phase Flow in Inclined Tubes with Specific Reference to Condensation: A Review. Int. J. Multiph. Flow 37, 845-859.

Meyer, J.P., Dirker, J., Adelaja, A.O., 2014. Condensation Heat Transfer in Smooth Inclined Tubes for R134a at Different Saturation Temperatures. Int. J. Heat Mass Transf. 70, 515-525.

Moreno Quibén, J., Thome, J.R., 2007. Flow pattern based two-phase frictional pressure drop model for horizontal tubes, Part II: New phenomenological model. Int. J. Heat Fluid Flow 28, 1060-1072.

Nebuloni, S., Thome, J.R., 2013. Numerical Modeling of the Effects of Oil on Annular Laminar Film Condensation in Minichannels. Int. J. Refrig. 36, 1545-1556.

Rayle, R.E., 1959. An investigation of the influence of orifice geometry on static pressure measurements. MIT.

REFPROP, 2005. NIST Thermodynamic Properties of Refrigerants and Refrigerant Mixtures, Version 8.0, NIST Standard Reference Database 23. National Institute of Standards and Technology. Gaithersburg, MD. National Institute of Standards and Technology, Gaithersburg, MD.

Rouhani, S.Z., Axelsson, E., 1970. Calculation of Void Volume Fraction in the Subcooled and Quality Boiling Regions. Int. J. Heat Mass Transf. 13, 383-393.

Suliman, R., Liebenberg, L., Meyer, J.P., 2009. Improved Flow Pattern Map for Accurate Prediction of the Heat Transfer Coefficients During Condensation of R-134a in Smooth Horizontal Tubes and Within the LowMass Flux Range. Int. J. Heat Mass Transf. 52, 5701-5711.

Thome, J.R., 2006. Condensation Inside Tubes, in: Engineering Data Book III. Wolverine Tube Inc., pp. 1-27.

Thome, J.R., Bar-Cohen, A., Revellin, R., Zun, I., 2013. Unified Mechanistic Multiscale Mapping of Two-Phase Flow Patterns in Microchannels. Exp. Therm. Fluid Sci. 44, 1-22.

Thome, J.R., El Hajal, J., Cavallini, A., 2003. Condensation in Horizontal Tubes, Part 2: New Heat Transfer Model Based on Flow Regimes. Int. J. Heat Mass Transf. 46, 3365-3387.

Van Rooyen, E., Christians, M., 2007. Time Fractional Analysis of Flow Patterns During Refrigerant Condensation. University of Pretoria. 
Van Rooyen, E., Christians, M., Liebenberg, L., Meyer, J.P., 2010. Probabilistic Flow Pattern-Based Heat Transfer Correlation for Condensing Intermittent Flow of Refrigerants in Smooth Horizontal Tubes. Int. J. Heat Mass Transf. 53, 1446-1460.

Wojtan, L., Ursenbacher, T., Thome, J.R., 2005. Investigation of Flow Boiling in Horizontal Tubes: Part I-A New Diabatic Two-Phase Flow Pattern Map. Int. J. Heat Mass Transf. 48, 2955-2969.

Woldesemayat, M.A., Ghajar, A.J., 2007. Comparison of Void Fraction Correlations for Different Flow Patterns in Horizontal and Upward Inclined Pipes. Int. J. Multiph. Flow 33, 347-370. 